\title{
QUE SI LES OÍAN REÑIR O MALTRATAR EL MARIDO A LA MUJER LA SOCORRIESEN: FAMILIA, VECINDAD Y VIOLENCIA CONTRA LA MUJER EN LA EDAD MODERNA
}

\author{
ANA MORTE ACÍN \\ Queen Mary University of London
}

Fecha de recepción: enero 2012

Fecha de aceptación: febrero 2012

A lo largo de las últimas décadas se ha incrementado el interés por el estudio de la violencia contra las mujeres en la Edad Moderna en toda Europa con la aparición de obras que han arrojado luz sobre un tema tan espinoso ${ }^{1}$. La preocupante situación que, al respecto, seguimos viviendo en la actualidad, hace que las cuestiones relacionadas con este tema cuenten con plena vigencia. Siguiendo a Antonio Gil Ambrona, la violencia contra la mujer, lejos de ser una respuesta a los movimientos feministas iniciados en el siglo XX, es fruto de una larga tradición que se remonta al inicio de los tiempos que legitimaba, en sus palabras, «una violencia ejercida por hombres y dirigida a someter, controlar o agredir física, verbal, emocional o sexualmente a mujeres con las que estaban o habían estado unidos» ${ }^{2}$.

\footnotetext{
1. Sobre todo se trata de obras que abordan los problemas matrimoniales que desembocaban, o eran causados en muchos casos, por la violencia contra la mujer. Por citar sólo algunos: MORANT, Isabel y BOLUFER, Mónica, Amor, matrimonio y familia, Madrid, 1998; Morgado GARCíA, Arturo, «El divorcio en el Cádiz del siglo XVIII», en Trocadero. Revista de Historia Moderna y Contemporánea, nº 6-7, 1994-1995, pp. 125-135; BORELLO, Benedetta, «Annodare e sciogliere. Reti di relazioni femminili e separazioni a Roma (XVII-XVIII secolo)» Quaderni Storici, 111, no 3, diciembre 2002, pp. 617-648; STONE, Lawrence, Broken lives: Separation and divorce in England 1660-1857, Oxford, 1993; CRAWFORD, Patricia y GowING, Laura, Women's worlds in 17th century England, Nueva York y Londres, 2000; DoLAN, Frances, Marriage and violence. The Early Modern Legacy, U. Pennsylvania Press, 2008; LILIEQUIST, Jonas, "Changing discourses of marital violence in Sweden from the age of Reformation to the late nineteenth century», en Gender and History, vol. 23, n 1, abril 2011, pp. 1-25.

2. Gil AmBronA, Antonio, Historia de la violencia contra las mujeres, Madrid, 2008, p. 23.
} 
En este trabajo el objetivo fundamental es mostrar cuáles fueron las diferentes actitudes que familiares, vecinos y amigos de las víctimas adoptaron ante el maltrato, actuando en la mayoría de los casos como la red de apoyo que las mujeres necesitaron para enfrentar la situación de violencia que vivían, ya fuera recurriendo a los tribunales o huyendo de sus casas. Un sostén que no consistía sólo en el apoyo material, sino también moral, puesto que, como veremos, las teorías de moralistas y filósofos de la época tendían a culpabilizar de cualquier problema matrimonial a la mujer que, sintiéndose responsable de su situación, difícilmente daba el paso de terminar con ella.

Familiares, vecinos o amigos aparecen ante nuestros ojos como piezas clave en la resolución o perpetuación del problema. En algunos casos, con sus testimonios y sus actos desafiaron la moral oficial de la época, poniendo de manifiesto, una vez más, la distancia que, muchas veces, separa el discurso teórico que rige una sociedad de la realidad de la vida cotidiana. En otros casos influyeron en la prolongación de la situación de violencia que padecía la mujer, al obligar a la víctima a volver a convivir con su agresor. En una sociedad en la que la mujer vivía en una perpetua minoría de edad, el entorno era indispensable para que contara con garantías de poder escapar de una situación de violencia.

Las fuentes que se han utilizado para este trabajo son fundamentalmente judiciales, desde denuncias por malos tratos a actos de conciliación, pero también se ha encontrado valiosa información en fuentes como los procesos de beatificación de algunas religiosas. Los casos aquí expuestos no se limitan a la península, sino que proceden también del ámbito americano, en concreto de la Nueva España. Unido a todo ello, un amplio conjunto de referencias bibliográficas de otros países europeos donde se describen situaciones similares a las del caso español, lo que nos permite observar cómo el uso de la violencia contra la mujer era un fenómeno que no distinguía de ámbitos geográficos, estamentos sociales, razas o credos religiosos.

Dado que, como se ha señalado, nuestro objetivo fundamental es observar el papel del entorno de la víctima, nos hemos circunscrito a la violencia dentro del matrimonio, poniendo el foco en la actitud que familiares, vecinos y amigos tuvieron ante el problema.

En el Antiguo Régimen el matrimonio era, ante todo, un contrato económico entre dos familias que buscaba, como fin último, la perpetuación del linaje o la subsistencia del grupo familiar. El componente romántico como base del matrimonio no aparecerá hasta siglos después con el Romanticismo y ni siquiera entonces se extendió a toda la población, por lo que es fácil comprender que las desavenencias dentro de los matrimonios fueran habituales.

Las familias jugaban un papel decisivo en la elección de los cónyuges de sus hijos e hijas, pero aunque los motivos económicos y sociales primaran en las negociaciones matrimoniales, tampoco cabe pensar que los padres no desearan la felicidad de sus hijos o que no les importaran en absoluto sus sentimientos. Por ejemplo, en Inglaterra se tiene conocimiento de la existencia de canciones populares de origen medieval en las que se advertía a las familias de que tuvieran cuidado a la hora de elegir a esposos para sus hijas, porque muchos podían parecer atractivos pero luego ser muy violentos 
y hacer desgraciadas a las muchachas. Se aconsejaba, sobre todo, evitar a los hombres que frecuentaban las tabernas y consumían alcohol, ya que bebida y violencia iban unidas en muchas ocasiones ${ }^{3}$. El equilibrio entre los aspectos socio-económico y sentimental era desde luego lo ideal, pero si uno de los dos debía primar ése era el salvaguardar los intereses familiares. Así que, posteriormente, cuando los padres tenían conocimiento de la infelicidad o el maltrato que sufrían sus hijas no se quedaban impasibles, sino que solían intervenir de diversos modos, lo mismo que habían hecho a la hora de acordar el matrimonio ${ }^{4}$.

En la sociedad estamental, el matrimonio, entendido como la unión legal entre un hombre y una mujer, era la base del sistema y, para el mantenimiento del orden y el buen funcionamiento del mismo, era primordial que esta institución fuera estable y dotase de estabilidad a la población. Cumplía, además, con un papel fundamental, el de proveer de súbditos a la Corona, socializar la jerarquía en su dimensión sexual y colaborar con el proyecto socio-político de la corona, en el que el orden social y la jerarquía eran pilares fundamentales. Así como el Rey estaba por encima de sus súbditos en la pirámide social, en el matrimonio la mujer estaba subordinada a su marido, lo que se traducía también en la legitimación del ejercicio de la violencia como modo de corregir el mal comportamiento de la esposa. Además, los altos índices de violencia que caracterizaban la sociedad de la Edad Moderna provocaban que el umbral de tolerancia frente a ésta fuera más alto que en la actualidad.

La mujer era considerada un elemento potencialmente desestabilizador de la sociedad y, por ello, era necesaria la supervisión y vigilancia de un varón, bien fuera su padre, un hermano o el esposo. A lo largo de los siglos, los autores cristianos habían elaborado y difundido por medio de sus obras, que se apoyaban en las Escrituras y la Patrística, una imagen negativa de la mujer. En ella, en contraposición con el hombre, se encarnaba todo lo pecaminoso que tenía el ser humano. Las diferencias fisiológicas eran consideradas signos de debilidad y flaqueza que se combinaban con un carácter lascivo, voluble y más proclive a dejarse arrastrar por las pasiones, lo que suponía que fueran un potencial peligro para el hombre, al que tendían a desviar de su camino espiritual hacia lo divino. Teniendo en cuenta lo anterior, es fácil comprender el papel que se reservaba a la mujer dentro del matrimonio: sumisión total al marido, superior a ella por naturaleza. Sólo con una disciplina férrea y con el esfuerzo de la mujer por controlar su naturaleza torcida, podía llegar a convertirse en el ideal de esposa que se describe, por ejemplo, en «La perfecta casada» de Fray Luis de León: una mujer dedicada al cuidado de su marido e hijos, ocupada en su casa de sol a sol, obediente y sobre todo casta, virtud indispensable para mantener su honra y, por ende, la de su familia ${ }^{5}$.

3. Lynn Martin, A., Alcohol, sex and gender in late medieval and early modern Europe Society, Chicago, 1987, p. 120.

4. FOYSTER, Elisabeth, «Parenting was for life not just for childhood: the role of parents in the married life of their children in Early Modern England», en History. The historical Association, 2001, p. 326.

5. Morant, Isabel y BolufER, Mónica, Amor, matrimonio...op.cit, p. 48. 
Para alcanzar este ideal, los moralistas de la época consideraban adecuado el castigo físico, reprobándolo sólo en los casos en que fuese desproporcionado o brutal. Se admitía, sin demasiados problemas, como medida de corrección de mujeres díscolas o que no cumplían con su papel de esposas adecuadamente. Azotar con moderación estaba socialmente bien visto, aunque debía evitarse, en la medida de lo posible, ya que alteraba el orden armonioso deseable dentro de la familia, siguiendo el mismo criterio aplicable a los niños o los criados ${ }^{6}$.

Unos golpes a tiempo podían ser útiles si así se evitaba que la persona se descarriase. Del uso correcto de la violencia sin miramientos, pero sometido a la razón, podía depender la bondad e, incluso, la excelencia del individuo en el futuro. La «corrección marital», que el marido infligiese castigos físicos a la mujer para corregir sus malos hábitos o «educarla», era una práctica habitual e incluso recomendada con moderación ${ }^{7}$.

Así pues, no se trataba sólo de la permisividad de la violencia, sino lo que era más determinante, la culpabilización de la mujer ante cualquier problema surgido en el matrimonio. Se le culpabilizaba de todo sistemáticamente, incluso de los problemas de fertilidad, que, para autores como Vives, eran un problema mayoritariamente femenino, e instaban a las mujeres que no se quedaban embarazadas a no culpar a sus maridos, sino a buscar la causa en ellas mismas ${ }^{8}$. Esa culpabilización se plasmaba posteriormente en el silencio y la aceptación del maltrato y dificultaba que esas mujeres se sintieran merecedoras de una salida. La solución no parecía poder buscarse tanto en la modificación del comportamiento del agresor, sino en la enmienda de los supuestos errores que cometía la víctima y que, a la postre, desencadenaban los comportamientos violentos del marido.

Autores de la talla de Erasmo, en sus obras referidas al matrimonio, definían perfectamente esta cuestión. En su Coloquio Mempsigamos, Eulalia, una feliz casada, y Xantipe, una mujer que sufre un matrimonio desgraciado, hablan acerca de las claves para tener un matrimonio dichoso. Entre los consejos que da Eulalia están el «sufrirle» mejor como era, que tratar de cambiarlo con «nuestra reciura» y, si se trataba de cambiar comportamientos adúlteros o violentos, sería mejor hacerlo por medio de la virtud y el sufrimiento 9 .

En la obra de Luis Vives el mensaje es el mismo. La mujer es la responsable de que haya armonía en su casa y, por tanto, las reacciones violentas del marido se deben siempre a errores, mal comportamiento o excesos de la mujer.

6. Morant, Isabel, Discursos de la vida buena. Matrimonio, mujer y sexualidad en la literatura humanista, Madrid, 2002. Similares discursos se utilizaban en los países protestantes, para el caso de Suecia ver: LILIEQUIST, Jonas, «Changing discourses of marital violence»... op. cit. p. 3.

7. García Herrero, $\mathrm{M}^{\mathrm{a}}$ del Carmen, «La marital corrección: un tipo de violencia aceptado en la Baja Edad Media», en Clío y Crímen, nº 5, 2008, p. 39-71.

8. Gil Ambrona, Antonio, Historia de la violencia...op. cit. p. 187.

9. Ibid., p. 180. 
Pero los ejemplos datan de mucho antes. Ya en las Confesiones de San Agustín podemos encontrar el modelo de mujer sacrificada en la figura de su madre, Santa Mónica, que, a pesar de sufrir a un «marido feroz», recomendaba a otras mujeres «después del contrato del casamiento en el cual mujeres se hacían cuasi siervas, deberían ellas de pensar en su estado y condición y acordarse de su suerte, no ensoberbeciendo contra sus maridos», para concluir que las que tomaban sus consejos y experimentaban lo que ella, «alegrábanse, y las que no, eran maltratadas y sujetas» ${ }^{10}$.

Aunque las obras de estos y otros autores no llegaran a la mayoría de la población, la idea de la culpabilidad de la mujer sí estaba muy extendida y los mensajes que los moralistas y teólogos difundían iban calando poco a poco, creando un clima de opinión claramente hostil a las mujeres. Si a ello se añade el, bien conocido en la actualidad, sentimiento de culpa que suelen desarrollar las personas víctimas de maltrato, es fácilmente comprensible que fuera difícil para las mujeres maltratadas encontrar argumentos morales a su favor que les permitieran rebelarse contra su situación.

Es complicado rastrear en las fuentes tanto el maltrato como el daño psicológico, ya que, normalmente, sólo se podía probar la existencia de heridas físicas. Sin embargo, sí parece razonable pensar que, detrás de la descripción de mujeres que se mostraban taciturnas, «melancólicas», introvertidas, que se apartaban de la familia y que llegaron incluso a suicidarse, está el daño psicológico producido por el maltrato, como en 1623, en Somerset (Reino Unido), cuando la justicia dictaminó que Anne Hannam había sufrido un colapso nervioso debido a la crueldad de su marido ${ }^{11}$, o Elisabeth Williams de Stoke Newington que demandó a su marido en 1619 alegando malos tratos. Los testigos declararon que las vejaciones a las que sometía a Elisabeth habían llevado a ésta a tener problemas mentales y encontrarse al borde de la locura ${ }^{12}$. Algunas mujeres llegaban a sentirse tan desesperadas que incluso recurrían a la brujería para conseguir que sus maridos murieran. En 1670 Peter Banks vendía un remedio mágico en Newcastle que garantizaba que hasta el marido más violento y cruel se convertía en una persona dulce y atenta ${ }^{13}$.

Cuando una mujer maltratada, bien por ella misma, bien por consejo de sus familiares o seres cercanos decidía buscar una solución a su problema, lo normal no es que acudiese inmediatamente a las autoridades. De hecho, ése solía ser el último paso de una larga serie de intentos de arreglar su situación en la intimidad. Varios factores contribuían a ello. Por un lado, como se ha señalado, el miedo y el sentimiento de culpa que provocaba que, en muchos casos, las mujeres se avergonzaran de su situación y no quisieran que saliera a la luz. También las obras de moralistas instaban a las mujeres

10. Agustín de Hipona, Confesiones, introducción y edición de, Tellechea Idígoras, J. Ignacio, Madrid,1996, Libro IX, cap. VIII p. 229.

11. CAPP, Bernard, When gossips meet. Women, family, and neighbourhood in Early Modern England, Oxford, 2003, p. 85.

12. GowING, Laura, Domestic dangers. Women, words and sex in Early Modern London, Oxford, 1996, p. 211.

13. CAPP, Bernard, When gossips meet..., op. cit. p. 85. 
a tratar de calmar a los maridos, usar buenas palabras o esperar a momentos propicios para intentar apaciguar sus ánimos; por ejemplo, esperar a que un marido borracho se encontrara sobrio para intentar hacerle entrar en razón sobre lo inadecuado de su comportamiento ${ }^{14}$.

Pero también el temor a mancillar la reputación familiar frenaba a algunas mujeres a la hora de dar a conocer su situación. La salida a la luz pública de las desavenencias en un matrimonio podía, fácilmente, volverse en contra de la mujer, a pesar de que fuera víctima de maltrato, ya que al ser la responsable de mantener la paz en el hogar, la falta de entendimiento con su marido era considerada su culpa. Y ese fracaso como esposa repercutía directamente en la reputación de su familia, ya que era responsabilidad de los padres educar y preparar a las hijas de forma adecuada para que fueran capaces de desempeñar su papel apropiadamente ${ }^{15}$.

En Inglaterra los tratados de buen comportamiento aconsejaban a la esposa acudir a los conocidos o a la justicia sólo in extremis y, en caso de dirigirse a la familia, mejor hablar con la del marido que con la suya ${ }^{16}$. Aunque en ocasiones la familia del marido no se mostraba muy conciliadora. Cuando en 1626 Marguerite Delavergne, vecina de Nantes, pidió ayuda a su cuñada para que le diera cobijo mientras solicitaba la separación, ésta le respondió que se había casado con su hermano para lo bueno y para lo malo, y que su obligación era aguantar pacientemente lo que le ocurriera ${ }^{17}$.

La familia de la víctima no solía permanecer impasible cuando se enteraba de la situación que la mujer estaba padeciendo. Normalmente les daban apoyo no solo afectivo sino también material, acogiéndolas en sus casas y actuando de testigos cuando era necesario. En ocasiones, además, se enfrentaron directamente con el agresor, poniendo en peligro su integridad física. Tal fue el caso de los padres de Isabella Sinclair que, en Kent en 1791, le dieron refugio en su casa por la amenaza que suponía para ella su marido. Cuando éste, llamado Alexander George, fue a buscarla a ella y a su hijo, sus suegros se enfrentaron a él golpeándole e incluso le llevaron a un río cercano donde le sumergieron la cabeza hasta que casi se ahogó. Para el padre de Ann Strenghtfield las cosas fueron peor. En agosto de 1707 presenció cómo su yerno amenazaba a su hija con una espada y trató de poner paz entre los esposos, pero su yerno, lejos de tranquilizarse, se enfrentó a él y le golpeó hasta dejarle malherido ${ }^{18}$.

En ocasiones el interés que los familiares de las víctimas tenían en la resolución de los problemas conyugales tenían también que ver con cuestiones económicas y sociales, sobre todo en lo concerniente al honor familiar y al mantenimiento del linaje, aunque nunca se puede excluir completamente el componente afectivo en las relaciones padres-hijos. Los intereses sociales y patrimoniales podrían estar detrás de

14. CAPP, Bernard, When gossips meet..., op. cit., p. 89.

15. Gil Ambrona, Antonio, Historia de la violencia..., op. cit., p. 198.

16. CAPP, Bernard, When gossips meet..., op. cit., p. 85.

17. HARDWICK, Julie, «Seeking separations. Gender, marriages and household economies in Early Modern France», en French Historical Studies, vol. 21 n $^{\circ}$ 1, invierno 1998, p. 165.

18. FoYsTER, Elisabeth, «Parenting was for life not just for childhood»..., op. cit., pp. 222-223. 
la actitud de algunos padres que, aun sabiendo la violencia que sufrían sus hijas, intentaron por todos los medios que volvieran con sus maridos y que no se rompiera el matrimonio. Más adelante veremos el caso de Pedro José de la Garza, que tras iniciar un proceso contra su yerno por los malos tratos que infligía a su hija, consintió que ella volviera con él a cambio del compromiso del marido de encontrar un trabajo y mantener a la familia.

Más dramático fue el caso de Solomon Daine, cuya hija se refugió en su casa por el miedo que tenía a su marido. Cuando él intentó convencerla de que volviera con él y evitar así el escándalo público, ella rompió a llorar y amenazó con suicidarse si le obligaban a volver. Poco tiempo después, aquejada por una enfermedad venérea que le había contagiado su marido, se vio obligada a permanecer recluida en su habitación ${ }^{19}$.

También los vecinos actuaban a veces guiados por su propio interés, y es que, en muchos casos, los maltratadores solían ser además vecinos problemáticos, que alteraban la convivencia y el orden social. Las mujeres solían ser las más dispuestas a ayudar a otras mujeres, y las amigas y vecinas eran normalmente las personas a las que una mujer maltratada acudía en busca de ayuda. No es de extrañar que sean mayoritariamente mujeres las testigos en los procesos contra maridos violentos. Algunas de estas mujeres actuaban también pensando en sí mismas, como Anne Dilke, que en 1620, en Leicester, entró en la casa de su vecina y se encaró con el marido de su amiga acusándole de pegarle. Le amenazó, además, con la posibilidad de que su mujer le abandonara si seguía comportándose así y, por último, le conminó a que no frecuentara más su casa ni hablase con su marido, temiendo, quizá, que pudiese ejercer una mala influencia sobre él. Un grupo de mujeres de Kent, en 1612, fueron aún más lejos y, para ayudar a una mujer maltratada, entraron una noche en su casa y entre todas apalearon a su marido ${ }^{20}$.

En cualquier caso, la actuación de vecinos y familiares no siempre conseguía buenos resultados, y en muchas ocasiones el marido, furioso, sintiéndose humillado, se volvía aún más violento con su mujer. Lo mismo ocurría en el caso de las denuncias. Si la mujer no conseguía una sentencia o una separación «de hecho» duradera, las consecuencias de haber llevado a su marido ante un tribunal solían ser nefastas; por ello, a pesar del creciente número de denuncias que se dieron en los siglos modernos, hay que tener presente que, normalmente, una mujer no denunciaba hasta que no sentía que se encontraba en una situación tan desesperada que no tenía nada que perder ${ }^{21}$.

En el Concilio de Trento se dictó doctrina sobre el sacramento del matrimonio, y aunque se definió el mismo como un vínculo perpetuo e indisoluble, existía una fórmula para, en la práctica, romper un matrimonio ${ }^{22}$. Hablamos de la separación de lecho y cohabitación. Durante la Edad Moderna se vivió un aumento progresivo del número

\section{Ibid, p. 326 .}

20. CAPP, Bernard, When gossips meet..., op. cit., p. 106

21. CARroll, Stuart, Blood and violence in Early Modern France, Oxford, 2006, p. 239.

22. El matrimonio sólo podía disolverse por la anulación o por la muerte de uno de los cónyuges. Ni católicos ni protestantes aceptaron el divorcio como forma de disolver un matrimonio. RODERICK, Phillips, Untying the knot. A short history of divorce, Cambridge, 1991, p. 1. 
de demandas de «divortium» (término empleado para llamar a la separación de lecho y cohabitación), lo que responde a diferentes razones, una de las cuales es que la Iglesia prefirió formar parte del proceso a quedar al margen de unas separaciones que se estaban produciendo de hecho, sin pasar por los tribunales.

La separación de lecho y cohabitación podía ser una solución para las mujeres que estaban sufriendo malos tratos en el hogar, pero para poder llevar a cabo el proceso con éxito necesitaban de la ayuda del entorno. Como señala Laura Gowing, los amigos y familiares eran tan importantes a la hora de acordar y celebrar un matrimonio como cuando éste se rompía ${ }^{23}$.

La ayuda se traducía no sólo en la participación en el juicio como testigos, sino también a la hora de proporcionar a la mujer un apoyo material y logístico. Por ejemplo, cuando se solicitaba la separación en la Monarquía Hispánica, el juez normalmente ordenaba el «secuestro» de la mujer, que significaba que debía salir de su casa y ser trasladada al domicilio de parientes o amigos donde se garantizase el honor y la seguridad de la mujer. Por tanto, era necesario para poder iniciar los trámites judiciales contar con una red de apoyo que permitiese que el «secuestro» se pudiera llevar a cabo y el juez lo admitiese.

Los procesos normalmente se prolongaban mucho en el tiempo, y un gran número, además, quedaba inconclusos, por lo que, en la práctica, los esposos pasaban a vivir separados de hecho, a la espera de una sentencia que podía no llegar nunca. Pero ir a juicio no estaba al alcance de todos. En un estudio sobre más de 200 casos de separación presentados en la Edad Moderna en Nantes, la gran mayoría correspondían a comerciantes y artesanos. Los grupos sociales más desfavorecidos no podían permitirse los costes de un proceso judicial y, en el extremo contrario, la nobleza y las familias más poderosas solían preferir solventar este tipo de asuntos en privado y que no saliesen a la luz pública ${ }^{24}$.

En otras ocasiones se presentaban denuncias por malos tratos ante la justicia civil, no buscando la separación, sino protección ante una situación de violencia. Por ejemplo, en 1713 en Monterrey, Nuevo León, se procesó a Miguel Luna por escándalo con su mujer Juana Yañez. En una primera declaración, Miguel, entendiendo que estaba preso injustamente solicitó al juez que le dejara en libertad, argumentando que: «por corregir y enseñar como Dios manda los maridos a las mujeres me tiene preso seis días hace hoy».

Miguel había sido encarcelado porque su mujer se había dirigido al alcalde mayor para pedir que la protegiera, pues creía que su vida corría peligro debido al maltrato que sufría por parte de su marido. Los jueces solían mostrarse receptivos a tomar medidas a favor de la mujer mientras se dilucidaba la verdad, por lo que se dictó una especie de «prisión preventiva» contra Miguel Luna, a la espera de realizar las pertinentes investigaciones sobre el caso. El origen de las desavenencias matrimoniales parecía

23. GowING, Laura, Domestic dangers. Women,..., p. 216.

24. HARDWICK, Julie, «Seeking separations...», op. cit., p. 164. 
estar en la diferencia de opiniones acerca de dónde establecer el hogar conyugal. De un lado, Miguel quería seguir viviendo en la casa de su madre y Juana, por su parte, quería vivir en casa de la suya, en la que el marido no se encontraba a gusto.

Miguel consiguió que el juez accediese a ponerle en libertad; sin embargo, fue obligado a firmar un documento en el que se comprometía a vivir «quieta y pacíficamente» con su mujer y a buscar un lugar donde vivir ellos dos solos, a pesar de que había sido la situación de pobreza lo que le había llevado a vivir con su madre, y también se comprometía a buscar un trabajo que le permitiera mantener a la familia ${ }^{25}$.

Esta clase de documento en el que el marido se obligaba a tratar bien a su mujer y vivir con ella pacíficamente, utilizado desde la Edad Media ${ }^{26}$, era habitual en la época moderna y constituía, además, uno de los modos de solucionar los conflictos matrimoniales para que no llegara a producirse una separación, o lo que podía ser más grave, llegar a una corte de justicia. Para que un tipo de acuerdo de esta naturaleza llegase a firmarse, los familiares y amigos jugaban un papel determinante. En el caso anterior no conocemos el grado de implicación del entorno de Juana en la resolución del problema, pero existen otros ejemplos en los que sí contamos con información sobre la actitud de los familiares de las víctimas.

En 1798 encontramos un caso en el que la familia de la mujer jugó un papel importante. Don Pedro José de la Garza denunció a su yerno Ramón Baez por el maltrato que ejercía contra su hija, María Dolores de la Garza. En su denuncia decía lo siguiente: «Me querello civil y criminalmente contra su referido marido D. Ramón Baez por los malos tratamientos, ultrajes y bofetadas con que se ha portado con mi hija sin motivo para ello, faltándola además de lo dicho a las debidas y precisas atenciones de su estado».

Para reforzar su denuncia, don Pedro aportó varios testigos que corroboraron la veracidad de las acusaciones. En sus declaraciones describieron como Ramón golpeaba sin motivo a su mujer «cubriéndola de sangre», insultándole siempre sin razón aparente.

Sin embargo, y a pesar de la certeza que don Pedro tenía del estado de violencia que sufría su hija, aceptó que su yerno saliera en libertad y volviese a convivir con María Dolores. Es decir, con su decisión, contribuyó decisivamente a perpetuar la situación, obligando a su hija a volver a casa con su maltratador. Ramón, a cambio de recuperar a su esposa, tuvo que firmar un documento en el que se comprometía a vivir pacíficamente con su mujer, a no volver a golpearla ni vejarla, y ponía como fiador a un vecino suyo, encargado desde entonces de velar porque el trato se cumpliese. Se comprometía también a buscar una ocupación que le permitiera mantener adecuadamente a su mujer, ya que hasta entonces, según el padre de María Dolores: «no se le ha conocido otra que la del juego, siendo esta la causa en que ya haya echado mano

25. Archivo Histórico de Monterrey (AHM), Causas Criminales, vol. 12, exp. 193.

26. García Herrero, $\mathrm{M}^{\mathrm{a}}$ del Carmen, «La marital corrección..., op. cit. 
de lo que él (don Pedro) declara ha dado a su hija y en los malos tratamientos que ha experimentado ${ }^{27}$.

La falta de una red social que amparara a la mujer, dejaba a ésta en una situación muy precaria. En muchos casos las condenaba a quedarse en casa y sufrir el maltrato durante el resto de sus vidas, pero para las que decidían huir solas, la situación no era mucho más prometedora. Huir adónde y con quién no eran preguntas fáciles de responder. Aun así, algunas mujeres, que no contaban con ningún tipo de apoyo, decidieron huir y dejar atrás todo lo conocido, incluso a sus hijos, porque no tenían ningún otro medio de poner fin al maltrato. Una opción podía ser refugiarse en un convento; si no podía ser para entrar como religiosa, al menos hasta que se encontrara una mejor solución. En Ágreda, a mediados del siglo XVII, encontramos dos casos de mujeres que huyeron de sus casas por miedo a sus maridos y buscaron refugio en el convento de concepcionistas. Ambos testimonios los encontramos en el proceso de beatificación de Sor María de Ágreda, abadesa del convento y persona a la que ambas se dirigieron para intentar solucionar su problema. La religiosa, con fama de santa, era una figura que contaba con prestigio dentro de la comunidad y se convirtió en punto de referencia para los habitantes de la zona que acudían a ella en busca de consejo y aceptaban sus dictámenes ${ }^{28}$.

En el primero de los casos se cuenta el caso de una mujer de «buenas prendas y sangre», cuya familia se implicó en la resolución del problema. La mujer se presentó en el convento por primera vez para pedir a Sor María que le ayudara a pedir a Dios sobre un problema que le atormentaba. Pasados los años, volvió a aparecer por el convento, esta vez vestida con prendas de varón.

La mujer, temiendo que su marido la matara porque tenía celos, había huido de su casa disfrazada de hombre. Según el relato, se llegó incluso a cruzar en el camino con su esposo que había salido a buscarla con intención de matarla, aunque no la reconoció ${ }^{29}$. Llegó muy alterada al convento donde se entrevistó con Sor María que se apresuró a ofrecerle ayuda. Mandó que se cerrara bien la puerta del locutorio, en el que se encontraba la mujer, para impedir que el marido pudiera entrar, y se le dio comida y ropa. Sor María escribió a D. Diego de Castejón y Fonseca, por entonces obispo de Tarazona, para que la acogiese en su casa hasta que se determinase qué se debía hacer ${ }^{30}$.

El marido llegó «colérico y furioso» al convento y, una vez que se sosegó, Sor María habló con él para intentar buscar una solución: «Como era tan grave el caso

27. AHM, Causas Criminales, vol. 32, exp. 562.

28. Sobre Sor María de Ágreda ver: MoRTE Acín, Ana, Misticismo y conspiración. Sor María de Ágreda en el reinado de Felipe IV, Zaragoza, 2010.

29. Este detalle en el relato es uno de los puntos sobre los que creemos que hay que tener reservas, puesto que el hecho de que fuese la intercesión de Sor María la que propiciase que no fuera reconocida por el marido, otorga una funcionalidad al dato, lo que podría significar que no respondiese exactamente a la realidad. Menos sospechoso nos parece el hecho de que saliese disfrazada de casa, con el objetivo de pasar más desapercibida entre la gente.

30. Archivio Segreto Vaticano (ASV), Congr. Riti, proc. 3206, testimonio de Sor Isabel María de la Cruz. 
pasaron muchos debates de ambas partes de los parientes», hasta que Sor María dio con la mejor opción, que fue que ambos entraran en un convento. En el proceso se hace un elogio a las infinitas virtudes de Sor María, que había propiciado no sólo que el hombre atendiese a razones y permitiese que su mujer profesara, sino que él mismo tomara los hábitos en el convento de San Julián en la misma villa ${ }^{31}$. Pero lo que a nosotros nos interesa es comprobar cómo, tras «muchos debates» entre las dos familias, lo que se acordó, seguramente para no llegar a juicio y manchar la reputación de ninguna de las partes, fue la separación física de los esposos; un acuerdo privado avalado por el prestigio de Sor María ${ }^{32}$.

Del segundo caso conocemos menos detalles. Una mujer, también temiendo por su vida, acudió a Sor María en busca de ayuda. No se dice nada de que perteneciera a un linaje poderoso ni se hace mención a su familia, por lo que parece que era una mujer que no contaba con apoyo familiar y, por ello, la abadesa puso en marcha un dispositivo que la protegiera involucrando a otras personas del pueblo: «no satisfecha la sierva del Señor con los medios que había puesto para su paz, hizo que unas personas muy virtuosas, y de su satisfacción estuvieran mucha parte de la noche en centinela cerca de su casa para que si les oían reñir o maltratar el marido a la mujer la socorriesen ${ }^{33}$.

No tenemos noticia de cómo terminó este caso porque en el proceso ya no se ofrecen más datos sobre la resolución final del mismo, si la mujer siguió en el domicilio conyugal, o también para ella, como en el caso anterior, se buscó un lugar donde viviera apartada de su marido, pero de nuevo tenemos la prueba de la importancia del entorno, en este caso los vecinos, a los que se les insta a ayudar a la mujer.

Efectivamente, eran los vecinos en muchas ocasiones los que actuaban ante los casos de maltrato que ocurrían cerca de sus casas, los que comparecían como testigos en los juicios o los que daban cobijo a las víctimas en sus hogares. A pesar de la aceptación de la violencia moderada hacia la mujer, la población no permanecía impasible ante situaciones en las que la mujer estaba siendo maltratada brutalmente por su esposo. En Inglaterra, Judith Pollard, en 1566, fue arrojada en mitad de la noche a la calle y se dirigió a casa de unos vecinos que habitualmente le daban cobijo cuando su marido la golpeaba. Mary Pollet llamó a la puerta de sus vecinos a las 2 de la mañana cubierta de sangre y tapándose con una sábana. Mary Watson en 1686 estaba demasiado asustada para volver a su casa tras una discusión con su marido y pernoctó en casa de unos vecinos. A la mañana siguiente el hombre se dirigió a su casa para apaciguar al marido antes de que Mary regresase ${ }^{34}$.

En Zaragoza, los vecinos de Pascual Segura y Margarita Calmarza testificaron en favor de ésta en 1566 en el juicio por malos tratos. Varios de ellos relataron cómo

31. ASV, Congr. Riti. Proc., 3206, f.192r-v. Testimonio de Sor Ángela María de San Bernardo.

32. Gil AMBrona, Antonio, «Las mujeres bajo la jurisdicción eclesiástica», en BIRRIEL SALCEDO, Margarita, Nuevas preguntas nuevas miradas: fuentes y documentación para la historia de las mujeres (siglos XIIIXVIII), Granada, 1992, p. 130.

33. ASV, Congr. Riti. Proc. 3206, f. 221r, Testimonio de Sor Isabel María de la Cruz.

34. CAPP, Bernard, When gossips meet..., op. cit., p. 105. 
una noche oyeron desde sus casas a Margarita gritar « ¡Ay, ayuda, que me mata!» y, al acudir en su auxilio a la casa, encontraron la puerta cerrada, lo cual no era lo habitual. Uno de ellos, en otra ocasión, en la que los quejidos de la mujer se oían desde la calle y, al comprobar que la puerta estaba cerrada por dentro, pudo ver a través de las rendijas cómo Pacual golpeaba a su mujer. Todo el vecindario sabía que Segura tenía relaciones con una viuda llamada Mariana y que a raíz de ello, además de pegarle, se había despreocupado de su manutención, por lo que intentaron ayudar a Margarita con su testimonio ${ }^{35}$.

También en el caso de Manuela Duport y su marido, igualmente residentes en Zaragoza, la declaración de los vecinos fue crucial. Se trata de una causa abierta contra Manuela en 1654 por intento de asesinato de su marido Antonio Duarte ${ }^{36}$. Antonio alegaba que su mujer se había ausentado del domicilio conyugal en diversas ocasiones sin motivo justificado y que una noche que su mujer le había preparado una sopa para cenar, vio en ella algunos grumos y notó un sabor extraño, por lo que pensó que se trataba de veneno y pidió a Manuela que la comiera ella también. Según la versión de Antonio ella rehusó tomar la sopa y le dijo que era clara de huevo. Esa misma noche él se sintió enfermo y a la mañana siguiente Manuela ya no estaba en su casa. La ausencia se prolongó durante algunos días y fue encontrada en compañía de un tal mosen Milianda, cuando según ella se dirigía a entrar en un convento.

La versión de los testigos de Manuela era radicalmente diferente. Felipe Sánchez, de oficio sastre, había vivido durante un tiempo alquilado en una habitación de la casa del matrimonio Duarte Duport. Mientras él vivió allí, Manuela trabajó cosiendo botones para ganar algo más de dinero, ya que, según el testigo, Antonio no quería trabajar, y la pareja había discutido en su presencia varias veces acerca de ese tema. Un día, incluso, Antonio había aparecido en casa con un daga y Felipe había tenido que interponerse entre ambos para que no agrediera a Manuela.

Otra testigo llamada Gertrudis Martínez, vecina de la pareja, declaró que había hablado con Antonio y que éste le había reconocido que lo del veneno era mentira, pero que estaba muy enfadado por las desapariciones frecuentes de Manuela y por eso había llevado a cabo la acusación.

Los testigos de Antonio habían sido dos de sus empleadas, madrastra e hijastra, que en el juicio se pusieron de su parte. Sin entrar a valorar si decían o no la verdad, es reseñable lo que dicen de Manuela. Ambas señalan que el matrimonio se llevaba muy mal y que en alguna ocasión Antonio había pegado a su mujer, siendo las peleas y las riñas constantes en el hogar. Alegaron, en contra de Manuela, que se ausentaba del domicilio en ocasiones y contaban el caso concreto acontecido mientras Antonio estaba hospitalizado en el Hospital de Nuestra Señora de Gracia de Zaragoza. En ese periodo Manuela se ausentó una noche de su casa, sin que ninguna supiera adonde había ido; sin embargo, apuntaron que se preocupó de que todos los días la mucha-

35. Archivo Diocesano de Zaragoza (ADZ), Causas criminales caja 10, exp. 27.

36. ADZ, Causas criminales, caja 54, exp. 5. 
cha llevara la comida y la cena a su marido al hospital. También mencionaron que, aunque Antonio intentaba «agasajarla y reducirla a que viviera en paz con él», ella siempre le despreciaba y no ponía interés en vivir «maridablemente» con su marido en su casa. Además, frecuentaba una casa situada enfrente de la suya adonde también acudía mosen Milianda, y sabían que allí «se hablaban» y suponía que debían «vivir mal» porque se decía que habitaban algunas mujeres que «no daban buen ejemplo con su modo de vivir». Así pues, los argumentos de estas testigos, que reiteramos eran a favor de Antonio, y sin entrar en la veracidad de sus palabras, apuntaban a que Manuela no se comportaba como una buena esposa, porque no se mostraba sumisa y obediente ante su marido, a pesar de que, como ellas mismas reconocen, él la había golpeado en alguna ocasión. Se ausentaba de casa, hablaba con otro hombre, frecuentaba una casa de dudosa reputación; Manuela pasaba a ser la culpable y responsable única de su situación y de haber llevado a Antonio a un extremo en el que no parecía que le cupiera otro modo de actuar.

Entramos aquí en un terreno interesante que nos permite observar qué discursos esgrimían tanto hombres como mujeres en los pleitos que tenían como telón de fondo las desavenencias conyugales. Tal y como ha estudiado Natalie Zemon Davis, es muy importante comprender cómo se construían los testimonios que se iban a dar en los pro$\operatorname{cesos}^{37}$. Las personas que testificaban sabían cuáles eran los argumentos más convenientes que debían exponer ante los jueces para defender su causa y lo que no es menos importante, cómo debían hacerlo. La construcción de estos relatos se hizo a lo largo del tiempo, con la transmisión oral de los mismos y teniendo en cuenta tanto la moral como la legislación de cada momento. No se trataba de mentir o inventar los testimonios, aunque hubo casos en que eso se dio, sino en buscar las fórmulas que reforzaran la declaración y aumentaran las posibilidades de obtener un veredicto favorable.

En el caso de las separaciones conyugales, los hombres esgrimían el adulterio de la esposa como la causa para querer obtener el «divorcio» y, en el caso de las mujeres, la violencia y todos los problemas derivados de ella, como la dilapidación del patrimonio familiar, aparecen como argumento en la gran mayoría de los casos a lo largo de toda Europa. Dado que, como ya se ha señalado, la violencia aplicada con moderación era algo admitido por la sociedad, cuando se denunciaban malos tratos los deposantes sabían que debían centrarse, sobre todo, en describir la crueldad y la desproporción de la violencia ejercida por el marido para que su testimonio tuviera algún peso. De ahí las abundantes descripciones de cómo había quedado el cuerpo de la mujer tras haber recibido una paliza.

Del mismo modo, cuando las mujeres debían declarar solían acotar su testimonio a la brutalidad de su marido y muy pocas veces hacían referencia a cómo se sentían o a describir su miedo. Se mostraban sumisas y asumían una parte de la culpa intentando aproximarse lo más posible al ideal de buena esposa imperante en esos momentos. Es

37. Zemon Davis, Natalie, Fiction in the Archives: Pardon Tales and their Tellers in Sixteenth Century France, Stanford, 1987. 
muy significativo observar cómo los mismos elementos se repiten en casi todos los testimonios de las mujeres: se muestran a sí mismas como buenas esposas no merecedoras del trato que reciben, pero sin parecer orgullosas, altivas o demasiado sentimentales. En algunos casos hacen referencia a su niñez, que habría transcurrido apaciblemente en una familia virtuosa, como prueba de su honestidad y de lo inmerecido del maltrato ${ }^{38}$. Además, no suelen aparecer ni insultos ni descalificaciones hacia sus maridos, lo que podría volverse en su contra al parecer poco decentes, sino que se ciñen al relato de la violencia desmedida que ejercen contra ellas.

Pero también en ocasiones en que tanto hombres como mujeres querían terminar con matrimonios infelices, hubiera o no maltrato de por medio, se recurría al relato de la violencia y el adulterio como únicos argumentos válidos para conseguirlo. En una «ballad» inglesa del siglo XVII, una mujer borracha y abusadora exageraba la violencia que sobre ella ejercía su marido hasta un punto en que sabía que sería considerado intolerable por la justicia y así conseguiría la separación ${ }^{39}$. En los casos en los en los que era el marido el que quería obtener la separación, alegaba adulterio por parte de la esposa y, si no era posible probarlo de ningún modo, intentaba presionar a la mujer para que ella alegara malos tratos y lograr así el fin del matrimonio. También hubo mujeres que, sabiendo que la justicia solía mostrarse receptiva a ordenar la separación preventiva de los esposos en caso de sospecha de maltrato, utilizaban este argumento para alejarse de su marido. Es decir, los argumentos que podían funcionar ante un tribunal eran conocidos, se sabía lo que «había que decir» en cada caso y como es natural, cada uno los utilizaba en función de su moral y sus intereses ${ }^{40}$. Teniendo en mente que ni todos los esposos eran malvados ni todas las esposas bondadosas y abnegadas podremos obtener una mejor imagen de la realidad de la época, sin olvidar que los recurrentes testimonios sobre violencia hacia las mujeres muestran inequívocamente la magnitud del problema existente.

La importancia de los familiares, amigos y vecinos no se reducía a los casos de malos tratos y era también crucial para poder condenar a los uxoricidas. A pesar de que ya no se pudiera hacer nada para salvar la vida de la mujer, hubo familias que buscaron que se hiciera justicia con sus hijas y aportaron para ello sus testimonios y utilizaron todos los recursos que tenían disponibles. Estos casos nos muestran también cómo, a pesar de que en muchas ocasiones los vecinos protegieron a las mujeres interponiéndose entre los cónyuges, acogiendo a la mujer en casa o intentando razonar con el marido, fueron muchos los casos también en los que nos encontramos con una actitud que, sin duda, debió estar muy extendida: la pasividad.

La concurrencia de lo privado y lo público en este tipo de casos, hacía que la sociedad los viera como un problema en el que no debían inmiscuirse, un problema familiar que no les tocaba a ellos solucionar. Estas prevenciones no se limitaban sólo

38. FOYSTER, Elisabeth, «Parenting was for life not just for childhood...», op. cit., p. 326.

39. CAPP, Bernard, When gossips meet..., op. cit., p. 106.

40. Gil Ambrona, Antonio, Historia de la violencia..., op. cit., p. 224. 
a su entorno, sino también tenían un carácter especial para los jueces que, en muchas ocasiones, entendían que no debían interferir. Se trataba de un asunto familiar y, por tanto, la protección a las mujeres ante la violencia que sufrían en sus hogares era muy difícil de obtener.

En el Antiguo Régimen el mantenimiento del orden social era uno de los pilares que sustentaba un sistema político no igualitario en el que la monarquía se situaba en el vértice de la pirámide social y política, por lo que los uxoricidios y los delitos que se producían dentro del hogar, suponían, en sí mismos, un dilema para el sistema. Los crímenes de esta naturaleza originaban un conflicto que enfrentaba, de una parte, a la preeminencia del poder real y sus instituciones sobre todos los súbditos y, de otro, a la autoridad del padre de familia sobre los miembros de la misma, cuyo origen estaba en las leyes divinas y el derecho natural.

Era indispensable que los jueces actuaran respetando el delicado equilibrio existente entre ambos derechos. Según la teoría política del momento, la figura del monarca se asemejaba a la del pater familias, por tanto, se hacía necesario determinar si el uxoricida había actuado dentro de los límites del derecho divino y natural que le otorgaban su autoridad o, por el contrario, se trataba de un hombre que había cometido un crimen dentro del ámbito familiar. No se trataba de una cuestión trivial, ya que si la autoridad del padre de familia era concebida como soberana y natural, lo mismo que la del monarca, en teoría sólo debería rendir cuentas a $\operatorname{Dios}^{41}$. Si ese tipo de autoridad era cuestionada, lo podría ser también la del rey y con ello el orden social existente.

También desde el punto de vista religioso el asesinato de una mujer a manos de su marido planteaba cuestiones delicadas, ya que el matrimonio como sacramento y, por tanto, vínculo indisoluble, cuyo fin último era que ambos cónyuges alcanzaran la salvación, se tambaleaba como concepto en el momento en que la mujer era asesinada por su marido, quien se supone que se debía encargar de protegerla y llevarla por el buen camino ${ }^{42}$.

Los casos de uxoricidio abundan en la documentación y su resolución dependía en buena medida de la capacidad y el interés por obtener justicia que tuviera la familia de la víctima. Si en los casos de malos tratos el entorno jugaba un papel fundamental en el destino de las mujeres, cuando se producía un fatal desenlace su familia seguía siendo su principal valedora. El interés de los familiares de la mujer difunta por conseguir una condena para el presunto asesino era lo que propiciaba que se abriera un proceso, sin embargo, en el caso de mujeres que no tenían a nadie que pidiese justicia por ellas, los crímenes casi nunca acababan en condena.

Es el caso de María Petra, que fue asesinada por su marido Miguel Luna, en Monterrey en 1799, y que acabó sin cumplir su condena. María Petra murió de una puñalada en la cabeza. A pesar de que hubo testigos de la agresión que testificaron, la

\footnotetext{
41. Pescador, Juan Javier, «Del dicho al hecho: uxoricidios en el México Central, 1769-1820», en Gonzalbo Aizpuru, Pilar y Rabell Romero, Cecilia, (coords.) Familia y vida privada en la historia de Iberoamérica, México, 1996, p. 374.
}

42. Ibid., p. 374. 
mujer no contaba con una familia poderosa que luchara por obtener una justa condena para Miguel, y la justicia se mostró relativamente benevolente con él a pesar de lo escalofriante de los hechos.

De acuerdo con las declaraciones de los testigos, María Petra se encontraba dentro de su casa en compañía de una vecina, testigo en el proceso, cuando Miguel entró en la casa y la acusó de decirle mentiras, comenzando así una discusión que terminó con la puñalada a María Petra. La vecina que se encontraba con ella salió a buscar a otra vecina llamada Claudia, y ambas sólo alcanzaron a sostenerla mientras moría entre sus brazos. Miguel huyó de la casa pero fue apresado nada más salir. El juez se trasladó a la hacienda donde se habían producido los hechos para examinar el cuerpo y comprobó que la difunta presentaba una profunda herida en la cabeza, de 4 dedos y medio. En su declaración Miguel afirmó que el demonio le había cegado, que pensaba que su mujer le engañaba y que sabía que había obrado mal, mostrándose arrepentido. Sin embargo, ninguno de los testigos confirmó la infidelidad de María Petra. Miguel fue encarcelado a la espera de juicio pero, a causa de una supuesta enfermedad, fue trasladado al hospital de donde se fugó en 1800 y no se volvió a saber nada más de él ${ }^{43}$.

Existen numerosos ejemplos en los que las mujeres no recibieron ninguna ayuda y acabaron siendo asesinadas por sus maridos, alegando los testigos que o no habían podido o habían preferido no hacer nada. Es el caso de Estefanía que fue asesinada a latigazos en 1714 por su marido, un mulato llamado José Gabriel, también en Monterrey. A pesar de que hubo varios testigos en el proceso que vieron la paliza tan sólo una persona, un vecino llamado Nicolás, se atrevió a intentar detener al agresor, pero él no atendió a razones. Nadie más actuó porque no querían entrometerse en un problema familiar, perteneciente al ámbito doméstico. Unas horas después de la paliza José Gabriel se acercó a casa de Nicolás y le dijo que su mujer estaba «más muerta que viva» tras lo cual huyó. Después de la muerte de Estefanía la justicia emitió una orden de búsqueda y captura contra él, pero no se dio seguimiento al caso, ya que la joven no tenía a nadie que luchase porque se hiciese justicia ${ }^{44}$.

En otros casos, la actuación de la familia de la víctima ayudó en última instancia a legitimar la actuación del asesino, como en 1657, cuando fue procesado un tal Domingo, «indio alazapa», por matar a su mujer Leonor. Domingo alegó en su defensa que Leonor era adúltera y que, ya en varias ocasiones, le había advertido de que si no dejaba de engañarle la mataría. Según el proceso, Leonor mantenía una relación extraconyugal con Vicente, un trabajador de la hacienda donde también ellos vivían y trabajaban. Domingo contaba además con una carta muy poderosa, y es que alegó que le contó a un tío de la víctima, Gabriel, y a otro amigo, Alfonso, lo que estaba ocurriendo y les pidió que hablasen con ella para que ésta acabara con su comportamiento. El tío de la víctima declaró en el juicio, corroborando, efectivamente, las palabras de Domingo. Explicó cómo habló con su sobrina y le recomendó que terminase con su

43. AHM, Causas Criminales, vol. 32, exp. 565.

44. AHM, Causas Criminales, vol.12, exp. 197. 
relación, ya que temía que Domingo llevase a cabo sus amenazas. Leonor desoyó sus advertencias y continuó viéndose con su amante, hasta que una noche en que Domingo estaba trabajando vigilando los campos de trigo, descubrió a su mujer y su amante teniendo relaciones sexuales y lleno de furia se abalanzó contra ellos. Vicente consiguió escapar pero Leonor murió allí mismo, víctima de las heridas que le provocó su marido.

Tras escuchar el relato de los hechos, los jueces entendieron que Domingo había hecho todo lo que estaba en su mano por conseguir que su mujer se comportara correctamente, pero dado que ésta no había cambiado su actitud, creían que era del todo comprensible que Domingo acabara con su vida. Fue puesto en libertad debiendo sólo pagar las $\operatorname{costas}^{45}$.

Domingo consiguió la absolución de acuerdo a varios factores. En primer lugar el adulterio femenino no tenía la misma consideración que el masculino. En el caso de la mujer se trataba de la mayor ofensa que podía hacer a su marido, por lo que se podía entender la cólera de Domingo. Pero es que, en segundo lugar, el esposo se había mostrado magnánimo en un primer momento y había intentado reconducir la conducta de su esposa, bien con advertencias, bien con la petición de ayuda al tío de Leonor. En tercer lugar, el hombre había matado a su esposa en un arrebato de ira sin premeditación, se entendía casi que sin querer. No era raro que los tribunales se mostraran benevolentes con los hombres que asesinaban a sus mujeres «por accidente» ${ }^{46}$, por lo que todos estos atenuantes no podían conducir a otro veredicto que a la absolución.

En una sociedad en la que la opinión generalizada era que la maltratada lo era por su culpa era difícil conseguir justicia. Es por eso que la actuación de los familiares, amigos y vecinos ante una situación límite era fundamental para que el caso fuera denunciado y se consiguiera una sentencia favorable. Que la mujer fuera escuchada dependía más que del delito del que hubiera sido víctima, de la respuesta que generase en su entorno. El mismo crimen en contextos o circunstancias diferentes no era visto igual ni por la sociedad ni por su entorno.

45. AHM, Causas Criminales, vol. 9, exp. 116.

46. VINYOLES, Teresa, «No puede aceptarse crueldad tan grande. Percepción de la violencia de género en la sociedad feudal», en CóRDOBA Llave, Ricardo (ed.), Mujer, marginación y violencia entre la Edad Media y los tiempos modernos, Córdoba, 2006, pp. 185-200. 